\title{
Abordagens Semióticas em Educação Matemática
}

\author{
Semiotic Approaches in Mathematics Education
}

\author{
Lourdes Maria Werle de Almeida* \\ ORCID iD 0000-0001-8952-1176
}

Karina Alessandra Pessoa da Silva**

ORCID iD 0000-0002-1766-137X

\begin{abstract}
Resumo
Nesta pesquisa examinamos produções publicadas no BOLEMA que tematizam a semiótica no âmbito das pesquisas da área de Educação Matemática. A questão que orienta nossa investigação é $O$ que revelam os artigos publicados no BOLEMA sobre as abordagens semióticas nas pesquisas em Educação Matemática? Com caráter de pesquisa inventariante, nosso artigo traz à baila um retrato das abordagens semióticas e identifica três enfoques semióticos: os pressupostos de Charles S. Peirce, os constructos teóricos de Raymond Duval e o enfoque ontosemiótico, cujo mentor é Juan D. Godino. O artigo apresenta elementos que consideramos relevantes em cada um destes enfoques, bem como as abordagens semióticas dos vinte e três artigos analisados. Uma discussão final revela o retrato de entendimentos e abordagens identificadas nos artigos e visa estabelecer algumas articulações entre elas. Finalmente, a partir das abordagens identificadas, vislumbramos delinear contribuições da semiótica para a Educação Matemática.
\end{abstract}

Palavras-chave: Educação Matemática. Semiótica. Estado da Arte.

\begin{abstract}
In this research, we analyze BOLEMA related to semiotics in the scope of researches in Mathematics Education. The question that guides our research is: What do the papers published in BOLEMA reveal about the semiotic approaches in Mathematics Education researches? So, our article brings to light the perspectives and issues that have been the focus of research about semiotics in Mathematics Education. We have identified three approaches in the research: the theory proposed by Charles S.Peirce; the theoretical constructs of Raymond Duval; and the ontosemiotic approach, whose mentor is Juan D. Godino. Our article presents elements that are considered relevant in each of these approaches, as well as the semiotic approaches of the 23 analyzed papers. Then, we present a summary that reveals the perspectives, issues, and understandings about semiotcs identified in the papers we analyzed and aim to establish some articulations between them. The article concludes with considerations about the contributions of semiotics in Mathematics Education.
\end{abstract}

Keywords: Mathematical Education. Semiotic. State-of-the-art.

\section{Introdução}

\footnotetext{
* Doutorado em Engenharia de Produção pela Universidade Federal de Santa Catarina (UFSC). Docente da Universidade Estadual de Londrina (UEL), Londrina, Paraná, Brasil. Endereço para correspondência: Rua Antonio Pisicchio, 155, Londrina, Paraná, Brasil, CEP: 86050-482. E-mail: lourdes@uel.br.

** Doutorado em Ensino de Ciências e Educação Matemática pela Universidade Estadual de Londrina (UEL). Docente da Universidade Tecnológica Federal do Paraná (UTFPR), Londrina, Paraná, Brasil. Endereço para correspondência: Avenida dos Pioneiros, 3131, Londrina, Paraná, Brasil, CEP: 86036-370. E-mail: karinapessoa@gmail.com.
} 
A semiótica como ciência dos signos vem sendo constituída ao longo do tempo e sob influência de pensadores de diferentes áreas e épocas.

John Deely, um filósofo e semioticista americano, ao escrever no ano de 2001 o prefácio do livro "The Conimbricenses: Some questions on signs", cujo autor é outro filósofo americano, John Patrick Doyle, apresentou uma evolução histórica bem detalhada da semiótica, cujo nome tem origem na palavra grega semeiotiké. Retomando aspectos dos romanos, gregos, passando pela Idade Média, Aristóteles, Descartes até os tempos modernos de Kant, Saussure e Peirce, Deely apresenta elementos de como, em diferentes épocas, vem se lidando com a conceitualização do signo, do latim signum, sua natureza e sua função no pensamento e na interação humana.

Segundo Sáenz-Ludlow e Kadunz (2016), Deely consegue revelar que a história e a constituição da semiótica, co-evoluíram durante séculos, tanto sincrônica, quanto diacronicamente. Assim, a estruturação de uma consciência semiótica emergiu sistematicamente da influência e repercussão que o uso dos signos tem nas diferentes áreas de conhecimento.

No que se refere a uma primeira aproximação da semiótica com a Matemática, conforme argumenta Luis Radford em D’Amore, Pinilla e Iori (2015), podem se identificar pelo menos dois aspectos relevantes. Primeiro, a concepção de Hilbert e outros formalistas, que concebem a Matemática como um sistema formal constituída por meio de axiomas expressos simbolicamente. Segundo, a concepção de Galileu, que revela que o mundo está escrito em linguagem matemática e assim, a Matemática poderia ser concebida como um instrumento de modelagem de fenômenos.

Estes dois aspectos fornecem indicativos de que o desenvolvimento da Matemática não é independente do desenvolvimento e da diversificação dos signos e seus usos para a estruturação do pensamento matemático.

Neste contexto, Radford, Schubring e Seeger (2008) reconhecem que a Educação Matemática é uma das áreas em que, sem dúvida, aplicações e repercussões da semiótica têm grande relevância. Segundo estes autores uma questão que merece atenção é: "O que, exatamente, a semiótica tem a contribuir para a educação matemática?" (RADFORD; SCHUBRING; SEEGER, 2008, p. vii).

Embora possa parecer antagônico, os mesmos autores já ponderam que a resposta para essa questão é, ao mesmo tempo, simples e complexa. Simples, se considerarmos que o fazer matemática é uma atividade que, eminentemente, lida com símbolos. Complexa, se levarmos 
em consideração que processos de pensamento, conceitualização e representação por meio de signos são subordinados a sistemas de simbolização, abstração e generalização que envolvem aspectos culturais, sociais e cognitivos que podem ser idiossincráticos.

Sob este ponto de vista a complexidade inerente à discussão da contribuição da semiótica para a Educação Matemática não ignora que a comunicação e a construção de significados em ambientes educacionais estão sempre entrelaçadas e são mediadas por signos. Estes aspectos têm recebido a atenção de pesquisadores interessados em compreender características e especificidades dos processos de ensino e de aprendizagem da Matemática.

O que se pode perceber é que a semiótica aparece associada à Educação Matemática desde os anos de 1990. Conforme aponta Presmeg (2006), a Conference of the International Group of Psycology of Mathematics Education (PME) e o International Congress of Mathematical Education (ICME) são eventos da área que vêm apresentando a semiótica como um dos eixos temáticos em sua programação. No Brasil, relatos de pesquisas e experiências fundamentadas em algum enfoque semiótico também podem ser observados em eventos científicos da área de Educação Matemática (ALMEIDA; SILVA; VERONEZ, 2015, CAZORLA; GUSMÃO, 2009, SANTOS; SANTOS, 2009), embora ainda não se possa identificar eixo exclusivo para esta temática As publicações com foco na semiótica, entretanto, parecem ser mais numerosas em revistas científicas da área.

Assim, neste artigo dirigimos nossa atenção para um periódico específico da área de Educação Matemática - o BOLEMA - Boletim de Educação Matemática. Trata-se de uma revista tradicional da área e que tem números regulares desde o ano de 1985. Nossa atenção, nesse artigo, é para as publicações da revista que tematizam a semiótica na Educação Matemática. A questão que investigamos é: O que revelam os artigos publicados no BOLEMA sobre as abordagens semióticas nas pesquisas em Educação Matemática?

Do ponto de vista metodológico, assumimos no artigo uma perspectiva em consonância com pesquisas denominadas de estado da arte cujo objetivo é "mapear e discutir uma certa produção acadêmica" (FERREIRA, 2002, p. 258). Pesquisas com esta característica são, segundo a autora, indicadas para a constituição de um campo teórico, uma vez que viabilizam o levantamento de informações e resultados, em certo espaço de tempo e de divulgação, sobre uma área de conhecimento. Elas podem também revelar que perspectivas, embora aparentemente autônomas, oferecem possibilidades de integração, ou mesmo de contradições, e indicar lacunas que precisam ser superadas.

Apresentamos na nossa pesquisa o levantamento dos artigos e uma análise de cada um deles no que se refere à abordagem semiótica. Sem tomar uma ou outra acepção com relação 
às abordagens identificadas, a síntese de cada artigo analisado revela encaminhamentos, pressupostos e conclusões dos autores. Uma discussão final revela o retrato de entendimentos e abordagens contempladas nas publicações do BOLEMA, estabelece uma articulação entre elas, vislumbrando delinear contribuições da semiótica para a Educação Matemática.

\section{Os artigos pesquisados e os enfoques semióticos identificados}

Os encaminhamentos da nossa investigação visaram a elaboração de um retrato das pesquisas publicadas no BOLEMA em termos do tratamento dado à semiótica no âmbito da Educação Matemática. Esta elaboração, bem como a discussão da relevância de elementos deste retrato para a Educação Matemática, são delineadas a partir da questão: $O$ que revelam os artigos publicados no BOLEMA sobre as abordagens semióticas nas pesquisas em Educação Matemática?

Para o levantamento dos dados referentes aos artigos que tematizam a semiótica, realizamos uma busca no BOLEMA nas publicações classificadas como artigos. Para as publicações no período de 2006 a 2016 disponibilizadas on-line na homepage da revista foram realizadas duas buscas, sendo uma com os termos semiótica/semióticas e outra com os termos ontosemiótica/ontosemiótico. Com essas buscas foram identificados trinta e sete artigos que apresentam algum desses quatro termos de busca em qualquer parte do texto. Com relação às publicações do período de 1985 a 2004, realizamos buscas com os mesmos termos no $C D$ BOLEMA Digitalizado e identificamos outros dois artigos.

Com isso, evidenciamos que autores de trinta e nove artigos publicados no BOLEMA de 1985 até 2016 fazem menção, em alguma parte do texto, a pelo menos um dos quatro termos: semiótica, semióticas, ontosemiótica, ontosemiótico.

Visando delinear um retrato das abordagens semióticas nas pesquisas em Educação Matemática publicadas no BOLEMA, realizamos uma leitura preliminar dos trinta e nove artigos identificados. Nesta leitura, constatamos que dezesseis dos artigos cujos textos completos estão disponíveis, embora contemplem algum dos quatro termos a que nos referimos, seus autores não fundamentam suas pesquisas em pressupostos da semiótica ou ontosemiótica na Educação Matemática. Outros vinte e três artigos, entretanto, correspondem a pesquisas que usam esses pressupostos. São estes últimos o foco da nossa investigação.

A leitura dos vinte e três artigos viabilizou-nos a identificação de três enfoques: aqueles fundamentados nos pressupostos de Charles S. Peirce (05 artigos); os que se fundamentam nos constructos teóricos de Raymond Duval, identificados em geral como teoria dos registros de 
representação semiótica (07 artigos); os que se valem do enfoque ontológico-semiótico, denominado ontosemiótica (11 artigos).

O Quadro 1 apresenta a identificação dos artigos examinados com relação aos enfoques caracterizados, o número de artigos em cada enfoque, os autores de cada artigo, bem como a publicação do BOLEMA em que consta o artigo. Referimo-nos aos artigos usando letra que identifica o enfoque e número subscrito que indica a ordem dos artigos. Assim, a letra D corresponde a um artigo que se fundamenta nos constructos teóricos de Raymond Duval, P um artigo que segue os pressupostos teóricos da semiótica de Peirce e a letra $\mathrm{O}$ corresponde a um artigo que versa sobre ontosemiótica.

\begin{tabular}{|c|c|c|c|c|}
\hline $\begin{array}{l}\text { Enfoque da } \\
\text { Semiótica }\end{array}$ & $\begin{array}{c}\text { Número } \\
\text { de } \\
\text { trabalhos }\end{array}$ & Autores & $\begin{array}{l}\text { Publicação do } \\
\text { BOLEMA }\end{array}$ & Código \\
\hline \multirow{7}{*}{$\begin{array}{c}\text { Teoria dos } \\
\text { Registros de } \\
\text { Representação } \\
\text { Semiótica } \\
\text { Raymond Duval }\end{array}$} & \multirow{7}{*}{7} & FLORES, C. R. & v. 19, n. $26(2006)$ & $\mathrm{D}_{1}$ \\
\hline & & KALEFF, A. M. M. R. & v. 20, n. $28(2007)$ & $\mathrm{D}_{2}$ \\
\hline & & $\begin{array}{l}\text { COUTINHO, C. Q. S.; SILVA, M. J. F.; } \\
\text { ALMOULOUD, S. A. }\end{array}$ & v. 24, n. 39 (2011) & $\mathrm{D}_{3}$ \\
\hline & & MONZON, L. W.; GRAVINA, M. A. & v. 27, n. $46(2013)$ & $\mathrm{D}_{4}$ \\
\hline & & HENRIQUES, A. C.; PONTE, J. P. & v. 28, n. $48(2014)$ & $\mathrm{D}_{5}$ \\
\hline & & $\begin{array}{l}\text { SILVA, F. A. F.; SANTIAGO, M. M. L.; } \\
\text { SANTOS, M. C. }\end{array}$ & v. 28, n. 50 (2014) & $\mathrm{D}_{6}$ \\
\hline & & GAGATSIS, A. et al. & v. 30, n. 54 (2016) & $\mathrm{D}_{7}$ \\
\hline \multirow{5}{*}{$\begin{array}{l}\text { Semiótica de } \\
\text { Peirce }\end{array}$} & \multirow{5}{*}{5} & SILVEIRA, L. F. B. & v. 9, n. 3 (1994) & $\mathrm{P}_{1}$ \\
\hline & & $\begin{array}{l}\text { MANECHINE, S. R. S.; CALDEIRA, A. } \\
\text { M. A. }\end{array}$ & v. 23, n. 37 (2010) & $\mathrm{P}_{2}$ \\
\hline & & OTTE, M. F.; BARROS, L.G.X. & v. 29, n. $52(2015)$ & $\mathrm{P}_{3}$ \\
\hline & & SILVA, K. A. P; ALMEIDA, L. M. W. & v. 29, n. $52(2015)$ & $\mathrm{P}_{4}$ \\
\hline & & $\begin{array}{l}\text { PANERO, M.; ARZARELLO, F.; } \\
\text { SABENA, C. }\end{array}$ & v. 30, n. 54 (2016) & $\mathrm{P}_{5}$ \\
\hline \multirow{11}{*}{ Ontosemiótica } & \multirow{11}{*}{11} & $\begin{array}{l}\text { CAZORLA I. M.; GUSMÃO, T. C.; } \\
\text { KATAOKA, V. Y. }\end{array}$ & v. 24, n. 39 (2011) & $\mathrm{O}_{1}$ \\
\hline & & $\begin{array}{l}\text { BLANCO, T.F.; GODINO J. D.; } \\
\text { PEGITO, J. A. C. }\end{array}$ & v. 26, n. 42A (2012) & $\mathrm{O}_{2}$ \\
\hline & & $\begin{array}{l}\text { FUENTE, A. C.; ARMENTEROS, M. G.; } \\
\text { MOLL, V. F. }\end{array}$ & v. 26, n. 42B (2012) & $\mathrm{O}_{3}$ \\
\hline & & $\begin{array}{l}\text { GODINO, J. D.; CASTRO, W. F.; AKÉ, } \\
\text { L. P.; WILHELMI, M. R. }\end{array}$ & v. 26, n. 42B (2012) & $\mathrm{O}_{4}$ \\
\hline & & ASSIS, A; FRADE, C.; GODINO, J.D. & v. 27, n. 47( 2013) & $\mathrm{O}_{5}$ \\
\hline & & $\begin{array}{l}\text { FIGUEROA, S. M.; ANCHORENA, S.; } \\
\text { DISTÉFANO, M. L. }\end{array}$ & v. 28, n. 48 (2014) & $\mathrm{O}_{6}$ \\
\hline & & $\begin{array}{l}\text { PINO-FAN, L.R.; GODINO, J. D.; } \\
\text { FONT, V. }\end{array}$ & v. 29, n. $51(2015)$ & $\mathrm{O}_{7}$ \\
\hline & & VÁSQUEZ, C. ; ALSINA, A. & v. 29, n. 52(2015) & $\mathrm{O}_{8}$ \\
\hline & & GORDILLO, W. ; PINO-FAN, L. R. & v. 30, n. 55 (2016) & $\mathrm{O}_{9}$ \\
\hline & & AZNAR, M. A. et al. & v. 30, n. 55,(2016) & $\mathrm{O}_{10}$ \\
\hline & & NIEVES, E.M. & v. 30, n. 55 (2016) & $\mathrm{O}_{11}$ \\
\hline
\end{tabular}

Quadro 1: Artigos que tematizam Semiótica na Educação Matemática Fonte: Elaborado pelos autores (2017). 


\section{Sobre semiótica e os enfoques identificados nos artigos do BOLEMA}

Embora a origem da semiótica seja antiga, os contornos de ciência lhe são atribuídos a partir da metade do século XIX e em locais e culturas diferentes. Duas tradições de pesquisa independentes são amplamente reconhecidas: a dos Estados Unidos, relativa a Charles Sanders Peirce e a de Ferdinand de Saussure na Europa, mais especificamente na Suíça. Além dessas duas tradições, outros contribuíram para a estruturação da semiótica tais como: Lev Semenovitch Vygotsky e Sergei Mikhailovich Eisenstein com a caracterização da mediação semiótica (VYGOTSKY, 1978); a caracterização da semiótica social associada ao linguista britânico Michael Halliday (HALLIDAY, 1978).

Passaria assim a se estruturar o que alguns chamam de consciência semiótica, cujos alcances se estendem pelas diferentes áreas de conhecimento e consideram aspectos sígnicos relevantes em cada uma delas.

No âmbito da Matemática, para além das concepções de Hilbert e de Galileu que delinearam as aproximações entre a semiótica e a Matemática, a teoria dos signos volta a despertar interesse na filosofia contemporânea. O que se pode observar é que os aspectos essenciais da teoria semiótica não variam, mas é lhes acrescentada outra ordem de considerações, mais precisamente as que se incluem na chamada pragmática e que consideram a relação do signo com seus intérpretes. A partir desta discussão o objeto da semiótica não é mais o próprio signo, mas o seu uso ou o comportamento semiótico.

Neste contexto, entre professores de Matemática ou pesquisadores, especialmente da área de Educação Matemática, parece haver um consenso de que não é possível compreender e operar diretamente com os objetos matemáticos, havendo a necessidade de signos para se ter acesso a eles. Estes signos são, por um lado, meios para pensar sobre objetos e relações matemáticas e, por outro, produtos de tais pensamentos.

É justamente esta relação intrínseca e indissociável entre objeto, signo e pensamento que vem ocupando professores/pesquisadores da área de Educação Matemática considerando que realizá-la e compreendê-la é a própria gênese da aprendizagem em Matemática. Neste contexto, a semiótica foi recebendo atenção de educadores/pesquisadores na área de Educação Matemática, tais como: a definição de sistemas de representação semiótica pelo educador francês Raymond Duval (DUVAL, 1995); a categorização dos objetos, articulando aspectos ontológicos e semióticos, dando origem a um enfoque caracterizado como ontosemiótico pelo educador matemático Juan Godino (GODINO, 2002). 
Raymond Duval, no seu livro mais recente Ver e Ensinar a Matemática de Outra Forma inicia suas argumentações nesta perspectiva de relações signo ${ }^{1}$ objeto, com uma questão relevante para pensarmos sobre o papel dos signos para a compreensão em Matemática: "Quais são os sistemas, as estruturas, as capacidades do sujeito necessárias ou mobilizadas para ter acesso aos objetos, diretamente ou por uma sequência de processos conscientes ou inconscientes?” (DUVAL, 2011, p. 16).

Esta questão, provavelmente, esteja no escopo daqueles que buscam na semiótica argumentos, indícios ou justificativas para pesquisas que, em alguma medida, associam a compreensão às representações dos aprendizes em Matemática.

No entanto, os encaminhamentos e mesmo os desdobramentos que estas pesquisas podem tomar vêm se ancorando em diferentes aportes teóricos fundamentados em um enfoque semiótico.

No presente texto, a partir do exame de artigos publicados no BOLEMA, identificamos que os pesquisadores vêm construindo suas argumentações, essencialmente, a partir de três enfoques semióticos: aqueles fundamentados nos pressupostos de Charles S. Peirce; os que se fundamentam nos constructos teóricos de Raymond Duval; os que se valem de um enfoque ontológico-semiótico, denominado ontosemiótica.

\subsection{A semiótica Peirceana}

Charles Sanders Peirce (1839-1914) foi um filósofo e matemático americano. Peirce tinha em mente, segundo Santaella (2008), a estruturação de uma doutrina capaz de compreender as estruturas do conhecimento e caracterizou a semiótica como ciência dos signos que tem por objetivo o exame dos modos de produção de significado e de constituição de conhecimento. Para Peirce um signo

[...] é aquilo que, sob certo aspecto ou modo, representa algo para alguém. Dirige-se a alguém, isto é, cria na mente dessa pessoa, um signo equivalente, ou talvez um signo mais desenvolvido. Ao signo assim criado denomino interpretante do primeiro signo. O signo representa alguma coisa, seu objeto. Representa esse objeto não em todos os seus aspectos, mas com referência a um tipo de ideia que eu, por vezes, denominei fundamento do signo (PEIRCE, 2005, p. 46).

Assim, na teoria peirceana o signo tem natureza triádica, sendo constituído por três componentes: o representámen, ou fundamento do signo, o objeto e o interpretante. A adição

\footnotetext{
${ }^{1}$ Duval (2011) apresenta uma discussão interessante identificando especificidades do que é um signo e uma representação. Ainda nesta seção trataremos dessa argumentação do autor.
} 
do terceiro componente - o interpretante - na conceitualização do signo e a estruturação das relações entre estes componentes, constitui uma mudança revolucionária na evolução histórica da semiótica. De fato, segundo Saénz-Ludlow e Kadunz (2016), a introdução do interpretante como o efeito que o signo provoca na mente do intérprete, é o reconhecimento irrevogável de Peirce de que cada pessoa constitui seu próprio processo de atribuição de significado.

Como fundador do pragmatismo, Peirce formula suas definições sobre signo com um indiscutível zelo em relação a uma ação possível, à experiência, e, embora primem pela abstração, segundo Santaella (2008), suas formulações acabam por dar conta das mais diversas situações concretas.

Assim, em suas teorizações, Peirce indica que tudo que aparece à consciência pode ser traduzido em termos de três elementos formais associados a toda e qualquer experiência: Qualidade, Reação e Mediação. Santaella (2008) interpretando estes termos argumenta que "o signo é um primeiro (algo que se apresenta à mente), ligando um segundo (aquilo que o signo indica, se refere ou representa) a um terceiro (o efeito que o signo irá provocar em um possível intérprete)” (p. 7). Esta interpretação da autora também está alinhada com a terminologia já definida por Peirce, considerando estes três elementos caracterizados como categorias fenomenológicas: a primeiridade, a secundidade e a terceiridade.

A Primeiridade refere-se à qualidade dos objetos, ao que está relacionado ao acaso, sem referência a alguma outra coisa. A Secundidade refere-se à experiência, às ideias de dependência, determinação, dualidade, ação e reação. A Terceiridade refere-se à generalização, continuidade, capacidade de construção de conhecimento. Para Santaella (2008), essas três categorias constituem as três modalidades possíveis de apreensão de todo e qualquer fenômeno, esteja ele ocorrendo na Física, na Matemática, na Biologia, na Música ou em qualquer outra área do conhecimento.

No âmbito da Matemática, fenômenos educacionais têm sido interpretados à luz da teoria pragmática de Peirce. Neste contexto, Garnica (2001) aponta a influência de Peirce em questões educacionais e destaca a preocupação do semioticista no que se refere à abordagem das operações matemáticas no ensino de Matemática. Segundo Garnica, as concepções peirceanas sobre educação influenciaram as reformas curriculares ainda no início do século XX e trazem influências para a constituição da Educação Matemática. Levando em consideração que toda e qualquer apreensão se dá por meio da linguagem, que os signos são justamente os meios que viabilizam a linguagem, que a Matemática, seu ensino e sua aprendizagem estão também associados à produção e ao uso de signos, podemos conjecturar que os constructos da semiótica peirceana podem servir para a análise de fenômenos no âmbito do ensino e da 
aprendizagem da Matemática. Nos artigos que examinamos, cinco ocupam-se justamente desta análise.

\subsection{Os registros de representação semiótica de Raymond Duval}

Raymond Duval é filósofo e psicólogo francês. Desenvolveu grande parte de seus estudos em Psicologia Cognitiva no Instituto de Pesquisa em Educação Matemática de Estrasburgo, na França, no período de 1970 a 1999.

Um aspecto relevante de seus estudos, conforme indicado em Duval (2011), é que em Matemática "A análise do conhecimento não deve considerar apenas a natureza dos objetos estudados, mas igualmente a forma como os objetos nos são apresentados ou como podemos ter acesso a eles por nós mesmos” (p. 15). Neste sentido, o interesse de Duval está, principalmente, no funcionamento cognitivo do aluno. Para ele, o pensamento é ligado às operações semióticas e, consequentemente, não haverá compreensão possível sem o recurso a essas representações.

A construção da teoria de Duval - A teoria dos registros de representação semiótica como é conhecida, se daria a partir de um enfoque interpretativo das teorizações de Peirce, de Saussure e de Frege ${ }^{2}$. Não está no escopo do presente artigo toda a estruturação da teoria de Duval. Todavia nos parece pertinente tratar de suas fundamentações, especialmente para a formalização do termo representação. Retomamos assim, alguns aspectos da teoria peirceana visando elucidar sua relação com definições de Duval.

Para Peirce (2005) a representação é uma função do signo e representar é “estar em lugar de, isto é, estar numa relação com um outro que, para certos propósitos, é considerado por alguma mente como se fosse esse outro" (p. 61). Peirce faz também uma relação entre signo e representação: "Quando se deseja distinguir entre aquilo que representa e o ato da representação, pode-se denominar o primeiro de 'signo' e o último de 'representação"” (p. 61). Em consonância com esta assertiva de Peirce, Duval (2011) defende que as representações podem mudar conforme os pontos de vista, os sistemas de representação. O objeto, entretanto, é invariante do conjunto de representações que lhe podemos associar.

Segundo Duval (2011), o projeto de Peirce visando descrever o papel dos signos e das representações compreendia, essencialmente, dois aspectos. Primeiro, a classificação da diversidade das representações. O segundo visava analisar não somente a produção dos signos

\footnotetext{
${ }^{2}$ Friedrich Ludwig Gottlob Frege foi um matemático, lógico e filósofo alemão. Trabalhando na fronteira entre a filosofia e a matemática, Frege foi um dos principais criadores da lógica matemática moderna.
} 
ou das representações, mas a sua interpretação numa perspectiva que se pauta na ideia de que conhecer algo não implica somente na produção, mas também na interpretação das representações desse algo.

Duval, no decorrer de suas estruturações pondera que teria sido nessa perspectiva que Peirce retomou sua definição de signo, passando a escrevê-la como: "Um signo, ou representação é algo que está para alguém com alguma finalidade e em relação a algum aspecto ou capacidade" (DUVAL ${ }^{3}, 2011$, p. 32).

Para estabelecer a sua denominação de representação semiótica, Duval (2011) esclarece então o que denomina de clivagem cognitiva entre signos e representações. Segundo o autor, ambos, o signo e a representação, na atividade de conhecimento

\begin{abstract}
cumprem uma função comum que é «se colocar no lugar de» o que eles representam ou designan e surgem da mesma exigência epistemológica fundamental que é jamais se confundirem com os próprios objetos. O que separa radicalmente as representações dos signos é a natureza da relação com os próprios objetos. A relação entre os signos e os objetos não contém nenhuma interação, mas é apenas uma relação de referência dependendo do sistema semiótico utilizado, a língua, um sistema de numeração, etc. $[\ldots]$

Todas as representações semióticas apresentam duas características que não encontramos nas unidades elementares que denominamos «signos». Primeiramente, elas têm uma organização interna que varia de um tipo de representação para outra. A organização de uma frase simples não é a mesma da de uma equação. A organização interna de uma representação gráfica não é a de uma figura geométrica ou de um esquema, etc. Depois, e não importa qual representação semiótica, existem sempre várias maneiras de distinguir as unidades de sentido ou os níveis de organização (DUVAL, 2011, p. 37-38).
\end{abstract}

Com alguns exemplos na Matemática, Duval pondera que os signos correspondem as coisas pelas quais é preciso começar para dar um sentido a algo. As representações, por sua vez, expressam esse sentido e revelam a interpretação que os intérpretes dão para esse signo. A partir dessa discussão, Duval (ano) passa a considerar uma outra linha divisória: a que distingue as representações semióticas e as representações não semióticas.

Para Duval (2011), as representações semióticas são, portanto, produções constituídas pelo emprego de signos pertencentes a um sistema de representação, os quais têm suas dificuldades próprias de significado e de funcionamento.

Para ser considerada uma representação semiótica é necessário que atenda a três atividades cognitivas: a formação de uma representação identificável, o tratamento e a conversão de uma representação para outra.

Embora a questão da necessidade das representações semióticas em Matemática seja orientada por dois aspectos - a referência aos objetos e a transformação em outras

\footnotetext{
${ }^{3}$ Texto original em inglês: "A sign, or representation, is something which stands to somebody for something in some respect or capacity."
} 
representações - importa mais nessas representações a potencialidade intrínseca de serem facilmente transformadas em outras representações semióticas. O reconhecimento de um mesmo objeto nas diferentes representações é um problema cognitivo e a sua dificuldade pode advir do fato de que representações diferentes podem ter demandas conceituais e cognitivas diferentes.

Neste contexto, há de se conjecturar que a diversidade de tipos de representações semióticas e o modo de funcionamento de cada uma delas são questões relevantes para a realização da atividade matemática e da compreensão do objeto matemático. As operações e as interpretações das diferentes representações semióticas constituem, assim, demandas cognitivas associadas à compreensão em Matemática.

Na construção de sua teoria, Duval assinala esta mobilização simultânea de ao menos duas representações. O autor defende também que a coordenação de diferentes representações, sobretudo de coordenações progressivas entre diversas representações construídas em diferentes sistemas semióticos, é condição para a compreensão em Matemática. Quanto mais completa for esta coordenação, mais o aluno se torna capaz de conhecer o objeto e de falar sobre ele.

Levando em consideração esta relevância atribuída por Duval às representações é que seus pressupostos têm orientado pesquisas na área de Educação Matemática. Nos artigos do BOLEMA que estamos analisando, em sete deles os autores pautaram suas argumentações no quadro teórico estabelecido por Duval.

\subsection{O enfoque ontosemiótico}

O enfoque ontosemiótico, reconhecido como Enfoque Ontosemiótico da Cognição e Instrução Matemática (EOS) vem sendo estruturado desde o início da década de 1990, tendo como mentor Juan D. Godino - professor da Universidade de Granada, na Espanha. Em termos gerais, Godino e seus colaboradores abordam a natureza dos objetos matemáticos, visando aproximações teóricas que consideram pressupostos do pragmatismo, da antropologia e da semiótica para compreender determinados aspectos dos objetos matemáticos, seu ensino e sua aprendizagem.

Segundo Godino, Batanero e Font (2014), suas elaborações decorrem da necessidade de elaborar modelos ontológicos e semióticos para tratar da questão do significado institucional e pessoal dos objetos matemáticos. 
Conforme sugerem Gusmão et al. (2011), o ponto de partida do EOS foi a formulação de uma ontologia dos objetos matemáticos. Numa perspectiva educacional que considera a Matemática como atividade de resolução de problemas, os objetos matemáticos emergem das próprias atividades matemáticas. Neste sentido o enfoque é semiótico porque atribui papel essencial às representações enquanto recursos de expressão e de comunicação na atividade matemática. Os conflitos semióticos neste contexto referem-se:

[...] a toda disparidade ou desajuste entre os significados atribuídos a uma mesma expressão por dois sujeitos (pessoas ou instituições) em interação comunicativa e podem explicar as dificuldades e limitações do ensino e aprendizagem implementadas (GODINO, 2002, p. 246).

O que o enfoque ontosemiótico estabelece então é uma caracterização dos significados, sejam pessoais sejam institucionais. Além disso, a identificação de diferentes tipos de objetos matemáticos que emergem da atividade matemática também é estabelecida, considerando atributos contextuais bem como características com relação à própria natureza dos objetos (se são elementos linguísticos, se são algoritmos, se são situações-problema, por exemplo).

Os objetos matemáticos têm natureza complexa e sua abordagem na sala de aula depende das diferentes instituições, dos livros utilizados, da prática matemática utilizada pelos professores para o processo de instrução nas diferentes circunstâncias educacionais.

O EOS considera cinco níveis para a análise didática do processo de instrução que permitem descrever e identificar a Matemática e descrever a interação produzida no processo de instrução e as normas que o regulam. Segundo Font, Planas e Godino (2010), o EOS propõe cinco níveis ou tipos de análise didática do processo de instrução: 1) Identificação de práticas matemáticas; 2) Elaboração das configurações de objetos e processos matemáticos; 3) Análise das trajetórias e interações didáticas; 4) Identificação do sistema de normas e metanormas; 5) Valoração da idoneidade didática do processo de ensino e aprendizagem.

Assis, Frade e Godino (2013, p. 736) argumentam que uma análise didática em termos dos diversos níveis de análise do EOS precisa descrever e explicar a aprendizagem e a forma como se dá sua produção, bem como a relevância da interação entre professor e aluno para essa produção.

Neste sentido, o EOS viabiliza a configuração e análise da instrução matemática, contemplando diferentes configurações didáticas, as práticas matemáticas associadas aos conhecimentos didático-matemáticos dos professores bem como as interações que consideram aspectos pessoais e institucionais do ensino e da aprendizagem. 
Abordagens relacionadas ao enfoque ontosemiótico vinculadas ao ensino e à aprendizagem sob uma análise cognitiva e epistêmica têm motivado pesquisadores, constituindo o quadro teórico em onze artigos publicados no BOLEMA.

\section{Retorno aos artigos: as sínteses construídas}

Nesta seção retomamos os vinte e três artigos examinados e identificados no Quadro 1 com a intenção de esboçar uma análise com relação à abordagem dos autores em cada enfoque semiótico.

\subsection{Artigos que se fundamentam na semiótica peirceana}

Dos vinte e três artigos examinados, cinco funadamentam-se nos pressupostos da semiótica enunciados por Peirce.

$\mathrm{O}$ artigo $\mathrm{P}_{1}$, (Silveira, 1994), consiste em um ensaio teórico em que o autor, apresentando a classificação de Peirce para as ciências como ele a fez na década de 1900, expõe relações estabelecidas entre a Matemática e a Filosofia bem como esclarece caracterizações realizadas por Peirce para a Matemática. Segundo o autor, Peirce em sua classificação, situa a Matemática como Ciência da Descoberta, sendo essa aquela que somente procura conhecer novas verdades ou que diz respeito à descoberta do que lhes é próprio. Considerando a natureza dos seus objetos, a Matemática constitui a ciência mais abstrata, não havendo entretanto, diferença essencial entre Matemática pura e Matemática aplicada.

Considerando o histórico de interesses de Peirce por áreas distintas da Matemática como álgebra, geometria, topologia, associadas ao seu desafio da Lógica dedutiva, o autor indica que Peirce teria tido seu mais profundo mergulho na filosofia da Matemática quando desenvolveu a teoria dos grafos existenciais em que a própria Matemática se projeta na realidade metafísica.

No artigo $\mathrm{P}_{2}$ (Manechine, Caldeira, 2010) as autoras fundamentam-se nas concepções de Peirce para embasar o processo investigativo com relação aos processos cognitivos e linguísticos de alunos das séries iniciais da Educação Básica. A pesquisa foi desenvolvida com alunos de idade entre 9 e 11 anos em situações experienciais, tendo como objetivo a apreensão dos conceitos de medida, escala, espaço e interpretação gráfica. Estes conceitos, entretanto, além de serem apreendidos como objetos matemáticos, foram também apreendidos como ferramentas para o entendimento do conceito de coexistência e competição de plantas no ensino de Ciências Naturais. 
As ações didáticas, fenômenos e relações entre fenônemos foram observadas e analisadas considerando a tríade pedagógica Sentir-Perceber/Relacionar/Conceituar. Esta tríade foi construída em consonância com as categorias fenomenológicas primeiridade, secundidade e terceiridade, caracterizadas na semiótica peirceana. A pesquisa concluiu que as ações didáticas viabilizaram aos alunos explorar os aspectos sígnicos dos instrumentos usados para a realização das medidas. Além disso, a apreensão de signos matemáticos a partir das situações de experimentação e observação favoreceu as reflexões dos alunos. E por fim, as pesquisadoras concluíram que as relações caracterizadas pelos níveis (Sentir-Perceber/Relacionar/Conceituar) servem como indicadores aos professores no que se refere à compreensão dos alunos com respeito aos objetos matemáticos.

No artigo $\mathrm{P}_{3}$ (Otte e Barros, 2015), os autores discutem a transição de uma interpretação ontológica para uma interpretação semiótica da Matemática a partir da questão $O$ que é a Matemática, realmente? No entanto, na visão de Otte e Barros (2015), esta questão precisa vir ancorada numa discussão filosófica em torno de outra questão: Em que sentido os objetos matemáticos existem?

Com relação a essa segunda questão, os autores argumentam que, se por um lado a operação com conceitos abstratos foi considerada inadequada e incerta, por outro lado, há o domínio dos índices extra lógicos que cumprem a sua função semiótica, estando diretamente presentes em nossa experiência. Segundo os autores, se a axiomática formal, em seus primeiros estágios, negou que a Matemática precisa de objetos, sendo ela apenas o raciocínio hipotéticodedutivo dos postulados, Peirce viu, "como ninguém antes dele havia visto, que o uso de índices é um modo de significação tanto indispensável quanto irredutível” (OTTE; BARROS, 2015, p. 760).

Assim, os autores concluem que a concepção peirceana de Matemática como raciocínio diagramático, apregoa que, se a Matemática, por um lado, não faz reivindicações existenciais, apenas descrevendo as possibilidades, por outro lado ela requer a utilização de índices a fim de representar afirmações ou fatos. Uma concepção semiótica da Matemática, concebendo-a como raciocínio diagramático, pode se revelar útil tanto para a Filosofia da Matemática quanto para a Educação Matemática.

As considerações no artigo $\mathrm{P}_{4}$ (Silva e Almeida, 2015) referem-se ao uso da semiótica peirceana para tratar de uma temática recorrente nas pesquisas da área de Educação Matemática: o significado. As autoras abordam, particularmente, a atribuição de significado em atividades de Modelagem Matemática desenvolvidas por alunos de um curso de Licenciatura em Química. Argumentam que, considerando as indicações de Peirce, a busca por evidências 
de significado pode se pautar na análise dos signos interpretantes usados e/ou produzidos pelos alunos durante o desenvolvimento da atividade de modelagem.

Usando elementos da teoria peirceana, as autoras de $\mathrm{P}_{4}$ identificam nos signos interpretantes produzidos pelos alunos indícios de atribuição de significado para o problema e para a Matemática usada na sua resolução. A descrição das ações dos alunos para o desenvolvimento da atividade elucida o movimento do significado e permite às autoras a identificação do que elas denominam um caminho do significado no decorrer da atividade. Este caminho vai sendo traçado na medida em que os alunos constroem novos signos interpretantes que revelam o significado e que, na perspectiva de Peirce, constituem um ciclo ad infinitum.

No artigo $\mathrm{P}_{5}$ (Panero, Arzarello e Sabena, 2016), os autores tratam do espaço de trabalho matemático relativo à introdução do conceito de derivada, especialmente, de função derivada. Os autores analisam, sob uma perspectiva da semiótica peirceana, como é conduzido o processo da definição da função derivada por dois professores italianos com seus alunos do último ano do Ensino Médio. As práticas observadas nesses professores referem-se ao que os autores caracterizam como generacidade, relativa ao ato de passar da derivada em um valor $x_{0}$ à derivada em um ponto $x$ genérico.

Os autores descrevem a atividade semiótica envolvendo os signos produzidos por esses professores com a finalidade de proporcionar aos seus alunos a visualização da função derivada. Neste contexto Panero, Arzarello e Sabena (2016), caracterizam os recursos semióticos dos professores como: produção de signos com determinada intenção; transformação de signos; e relação entre signos e significados. O que os autores do artigo concluem é que o espaço do trabalho matemático é construído em torno dos signos produzidos e articulados na atividade da definição da função derivada.

\subsection{Teoria dos registros de representação semiótica caracterizada por Duval}

Conforme indica o Quadro 1, sete dos artigos examinados fundamentam-se nesse enfoque semiótico.

No artigo $\mathrm{D}_{1}$ (Flores, 2006) é realizada uma abordagem histórica e epistemológica com relação ao funcionamento e à constituição de um sistema de representação semiótica que rege a construção dos saberes. Considerando que "os objetos matemáticos, não sendo acessíveis pela percepção, só podem sê-lo por sua representação" (p. 3), a autora procura "compreender os fundamentos do estudo dos registros de representação semiótica para a aprendizagem em matemática, desenvolvido por Raymond Duval" (p. 20) e conclui que "os registros de 
representação semiótica são essenciais tanto para a criação de objetos matemáticos como para a sua apreensão" (p. 1).

Na pesquisa são abordados elementos que constituem a base da teoria de Duval aplicada à aprendizagem matemática: a representação na constituição do conhecimento instaurado na Idade Clássica; a definição de um sistema de representação com base na dicotomia entre sujeito e objeto; a relação do signo com um significante e um significado; os sistemas semióticos de representação. A autora indica também que os aspectos representativos tratados na teoria de Duval podem ser incorporados na formação de professores visando uma oposição ao modelo de racionalidade técnica ainda vigente em algumas instâncias de cursos de formação.

A pesquisa relatada em $\mathrm{D}_{2}$ (Kaleff, 2007) é pautada na teoria de Duval e visa uma análise cognitiva da atividade de conversão para categorizar obstáculos cognitivos evidenciados na resolução de problemas envolvendo conceitos geométricos não-euclidianos em cursos de formação de professores de Matemática. A autora analisou o comportamento dos participantes de dois cursos de formação de professores durante a resolução de um problema de Matemática discreta visando "capturar os sistemas de registros semióticos utilizados no processo de resolução do problema e entender de que forma o sujeito percebia os objetos matemáticos envolvidos no procedimento de resolução" (p. 71).

Para categorizar os obstáculos cognitivos a autora analisa as conversões entre dois registros, discursivos ou não-discursivos, e o fenômeno de congruência semântica. A análise evidencia que os participantes usam predominantemente registros gráficos que, em geral, não são apropriados ao contexto em estudo e conclui que os obstáculos cognitivos se apresentam "tanto em situações envolvendo somente um registro semiótico, quanto naquelas que demandam conversões" (p. 92).

Os autores de $\mathrm{D}_{3}$ (Coutinho, Silva e Almouloud, 2011), com base na teoria de Duval, investigaram "as relações entre o uso de diversos registros de representação semiótica [...] para o desenvolvimento do pensamento estatístico, particularmente a transnumeração" (p. 504) de dois professores da Educação Básica. Esses professores trabalharam em conjunto para resolver um problema visando à determinação das dimensões adequadas para o mobiliário de um refeitório escolar.

Levando em consideração a noção de apreensão de uma figura geométrica proposta por Duval, os autores propõem quatro formas de apreensão de um gráfico ou tabela estatística perceptiva, discursiva, sequencial e operatória. Os autores consideram que na resolução do problema os participantes, embora tenham realizado conversões e tenham cumprido as etapas do processo de transnumeração, não avançaram na articulação entre as quatro apreensões para 
uma análise mais consistente do problema. Assim, os autores inferem que "apenas o trabalho com tabelas e gráficos, mesmo que partindo da formulação da questão, coleta e organização dos dados, não é suficiente para provocar a evolução no desenvolvimento do pensamento estatístico" (p. 510).

Utilizando ferramentas digitais de mediação semiótica, as autoras de $\mathrm{D}_{4}$ (Monzon, Gravina, 2013) desenvolveram e testaram com alunos do Ensino Médio um objeto digital de aprendizagem para o estudo de números complexos e de funções por meio de animações interativas nas quais é possível realizar tratamentos e conversões entre registros algébricos e geométricos.

Para a construção do objeto de aprendizagem as autoras levaram em consideração a importância de "recursos para conversões entre registros; recursos para o desenvolvimento de esquemas de uso sintonizados com os procedimentos que caracterizam o pensamento matemático" (p. 650), em sintonia com aspectos da teoria de Duval.

A intenção de realizar animações interativas juntamente com questões para serem respondidas com poucas intervenções do professor adicionou ao objeto digital a característica de favorecer aprendizagens com maior autonomia por parte do usuário. Com a aplicação do produto, as autoras inferiram que, com o apoio de ferramentas digitais de mediação semiótica, é possível introduzir conteúdos no programa da Matemática escolar, bem como desenvolver novas propostas de ensino.

Em D 5 (Henriques e Ponte, 2014) é feita uma análise dos modos como as representações escolhidas por três alunos do Ensino Superior em atividades de investigação na disciplina de Análise Numérica dão suporte aos processos de raciocínio - indutivo e dedutivo.

Para a investigação, foram propostas duas tarefas apresentadas aos alunos por meio de um enunciado escrito para que, em duplas ou em trios, fossem confrontados com problemas que exigiram a utilização de diversas representações. Levando em consideração a diversidade de representações matemáticas para o desenvolvimento e a compreensão dos processos de raciocínio dos alunos, os autores do artigo, com base na teoria de Duval, analisam os tipos de registros - monofuncionais e multifuncionais - e as transformações de representações semióticas - tratamento e conversão.

Os autores concluíram que, embora uma diversidade de representações tenha favorecido a compreensão, utilizando tanto raciocínio indutivo como dedutivo, “é necessário dar atenção a alguns processos de raciocínio em que se verificaram maiores dificuldades, como a generalização e a justificação, que estão menos presentes no seu trabalho" (p. 295). 
Com o objetivo de identificar as representações e os significados de números racionais contemplados no Exame Nacional do Ensino Médio - ENEM, o artigo D6 (Silva, Santiago e Santos, 2014) apresenta um levantamento realizado nos itens do exame no período de 1998 a 2011. Os autores consideram como significados de números racionais: a medida (parte-todo), o quociente, a razão, o operador multiplicativo, a probabilidade, a localização do número na reta numérica e a porcentagem.

Considerando possíveis estratégias que poderiam ser realizadas para a resolução de cada item do exame, os autores evidenciaram que "as conversões entre os registros dos números racionais ocorreram apenas num sentido, com exceção de um item do ENEM 2010, em que a conversão pode ser mobilizada nos dois sentidos” (p. 1501). Mas entendem, fundamentados em Duval, que saber realizar a conversão de um registro para outro não implica em saber realizar a conversão inversa, visto que o sentido da conversão envolve estruturas cognitivas distintas. Com relação aos significados, os autores destacam que aqueles relacionados ao quociente e à localização do número na reta numérica não aparecem nas provas dos ENEM, o que denota a necessidade de reflexão sobre os critérios de escolha dos itens relativos aos números racionais inseridos no exame.

No artigo $\mathrm{D}_{7}$ (Gagatsis et al., 2016), os autores investigam o espaço de trabalho matemático no plano epistemológico relativo às representações semióticas dos números racionais em dois domínios matemáticos: a fração e o número decimal. A investigação visa explorar a flexibilidade dos alunos para lidar com as diferentes representações do número racional e é realizada com cerca de 1700 alunos com idades entre 10 e 14 anos, frequentando diferentes séries do Ensino Funadamental e Médio. Com esta finalidade os autores consideram o espaço de trabalho matemático relativo às transformações de tratamento e de conversão caracterizados na teoria dos registros de representação semiótica de Duval.

Os autores ponderam que uma contribuição relevante de sua pesquisa é a identificação de níveis hierárquicos no trabalho de representação dos números racionais. Do ponto de vista semiótico, concluem que há um crescimento regular e sistemático de um nível para outro em termos de sofisticação e refinamento nos tratamento em cada sistema representacional dos racionais, bem como na conversão entre os registros dos dois sistemas de representação ou dos dois domínios da Matemática para os números racionais. 


\subsection{Artigos sob o enfoque ontosemiótico}

Dos vinte e três artigos examinados, onze referem-se a pesquisas fundamentadas no enfoque ontosemiótico.

A análise da validade de uma sequência didática denominada "Os passeios aleatórios da Mônica" desenvolvida pelas autoras para o ensino de probabilidade constitui o foco da pesquisa descrita no artigo $\mathrm{O}_{1}$ (Cazorla; Gusmão, Kataoka, 2011). Trata-se de um conjunto de atividades disponíveis em objeto de aprendizagem digital para subsidiar o ensino dos conceitos básicos de probabilidade, tanto no ambiente papel e lápis, quanto no virtual.

Participaram da pesquisa alunos de um curso de especialização em Ensino de Ciências e Matemática, sendo a maior parte professores da Educação Básica e o encaminhamento metodológico da pesquisa está alinhado com uma pesquisa-ação.

Num Enfoque Ontosemiótico da Cognição e Instrução Matemática (EOS), as pesquisadoras se propuseram a realizar o que denominaram técnica de análise semiótica, olhando para os objetos matemáticos caracterizados como entidades primárias e presentes nos textos matemáticos. Neste caso, as análises contemplaram a linguagem, a representação, os conceitos, os procedimentos e os argumentos dos professores.

Com relação à relevância da análise semiótica, as autoras argumentam que "A utilização da técnica de análise semiótica do EOS vislumbra resultados consideráveis para a proposta de nosso trabalho, uma vez que nos permite um olhar mais atento e detalhado sobre os objetos implicados na atividade matemática, dando lugar a uma avaliação da sequência com vistas a um melhor planejamento, delineamento e eficácia no seu uso" (p. 558).

Aplicando a noção de configuração de objetos e processos introduzida no enfoque ontosemiótico do conhecimento e instrução matemática, a investigação $\mathrm{O}_{2}$ (Blanco, Godino e Pegito, 2012) avaliou a capacidade de visualização e raciocínio espacial dos estudantes. Com esse objetivo, os autores investigaram os processos e as capacidades dos estudantes para realizar tarefas em que são requeridas representações matemáticas externas - ostensivas - e representações internas - não-ostensivas - dos objetos geométricos espaciais e realizar operações ou transformações geométricas com os mesmos. Os autores afirmam que é possível "proporcionar um ponto de vista complementar para identificar a diversidade de conhecimentos que se coloca em jogo na realização de tarefas de visualização e raciocínio espacial” (p. 42), permitindo inferir sobre dificuldades associadas a esses tipos de tarefas. Nesse sentido, é possível construir categorias de objetos que auxiliam na distinção entre entidades mentais e 
institucionais, levando em consideração as configurações epistêmicas e cognitivas presentes nos processos de visualização e raciocínio espacial.

Para a análise semiótica das resoluções da atividade matemática proposta, os autores identificaram objetos e as relações primárias - linguagens, conceito, proposições, procedimentos e argumentos - que os alunos utilizaram. Com base na elaboração de uma configuração epistêmica associada à resolução da tarefa, os autores constituíram uma referência para estudar as configurações cognitivas dos sujeitos e, detectando coincidências e discrepâncias nas resoluções, formularam possíveis conflitos entre significados pessoais e institucionais, indicando suas possíveis causas.

A pesquisa descrita em $\mathrm{O}_{3}$ (Fuente, Armenteros e Moll, 2012) teve como objeto de estudo o ensino da noção intuitiva de limite de uma função, entendida como "o ensino do limite de uma função por aquela que não entra na formalização do limite mediante $\delta$ e $\varepsilon$ ” (p. 667). A análise é fundamentada no enfoque ontosemiótico da cognição e instrução matemática, em que é feita a descrição, a explicação e a avaliação da aula. A partir de situações-problema propostas, segundo uma trajetória didática sob uma configuração dialógica, alunos e professor dialogam. Nessa configuração, o professor tem o papel de formular e validar o diálogo e os alunos são responsáveis pela exploração das questões propostas pelo professor. A configuração didática "permite realizar uma análise detalhada dos processo de instrução matemática" (p. 674).

Com a investigação da prática matemática - em um sistema de práticas operativas e discursivas - desenvolvida na pesquisa, os autores detectaram conflitos semióticos nos alunos desencadeados pelos discursos do professor. Esses conflitos, de certa forma, interferem no significado institucional implementado. Nesse sentido, afirmam que "a representação gráfica, numérica e simbólica é imprescindível para a aprendizagem do conceito" (p. 687), de limite de uma função.

Baseando-se nos tipos de objetos e processos matemáticos introduzidos no enfoque ontosemiótico do conhecimento matemático que intervêm na prática matemática, a pesquisa desenvolvida em $\mathrm{O}_{4}$ (Godino, Castro, Aké e Wilhelmi, 2012) aborda maneiras de conceber o raciocínio algébrico desde a escola primária. Para os autores, epistemicamente, se faz necessária "uma mudança de foco de atenção desde os apectos simbólicos e procedimentais até o aspectos estruturais do raciocínio algébrico" (p. 487).

Os autores argumentam que é preciso considerar, conjuntamente, processos de generalização e simbolização - ou representação - e outros objetos considerados algébricos, tais como relações binárias, operações, funções e estruturas. Os autores destacam que "a 
generalização é uma característica do raciocínio algébrico, assim como os meios para simbolizar, tanto as situações de generalização, como as de indeterminação" (p. 488).

Levando em consideração os objetos e processos vinculados às práticas operativas e discursivas realizadas por uma pessoa para abordar a solução de um problema ou tarefa de uma atividade algébrica, os autores propõem uma tipologia de configurações algébricas que permite definir graus de algebrização da atividade matemática. Estas configurações fundamentam-se na classificação para objetos matemáticos proposta pela ontosemiótica.

Considerando que o EOS propõe cinco níveis ou tipos de análise didática, a investigação realizada em $\mathrm{O}_{5}$ (Assis, Frade e Godino, 2013) utilizou como modelo teórico-metodológico o nível 3 - trajetória didática e interações didáticas - e a identificação de padrões de interação, descritos por Godino e Llinares (2000) e Menezes (2005), para investigar como os diferentes padrões de interação, mobilizados por professoras e alunos, são articulados para otimizar a aprendizagem matemática.

A finalidade da investigação se pautou em inserir os alunos em uma "modalidade sociointeracionista de aprendizagem baseada na exploração, investigação e trabalho cooperativo“" (p. 741). Para isso, foram implementadas atividades exploratório-investigativas em aulas de Matemática do sétimo ano do Ensino Fundamental com as quais foram identificadas configurações didáticas que possibilitaram descrever e interpretar processos interativos na sala de aula.

Com o objetivo de avaliar o que denominam um processo de instrução sobre o Teorema de Bayes, os autores de $\mathrm{O}_{6}$ (Figueroa, Anchorena e Distéfano, 2014) utilizaram o enfoque ontosemiótico nas configurações epistêmica e cognitiva da idoneidade didática, que corresponde à "pertinência ou adequação de um processo de instrução" (p. 174). Quando utilizada para a avaliação de um processo de instrução, a aplicação dos critérios da idoneidade didática permite guiar o processo de validação e uma possível melhoria no referido processo de instrução e na aprendizagem.

Inicialmente os erros dos alunos com relação à probabilidade condicional foram sondados mediante uma metodologia em que situações-problema foram propostas aos alunos. Posteriormente, ocorreu o processo de instrução do teorema de Bayes seguido de outras situações-problema em que foi investigado se os erros ainda permaneciam na resolução dos alunos. A partir das produções dos alunos realizadas antes e após o processo de instrução, as autoras construíram configurações epistêmicas (relacionadas às práticas institucionais) e cognitivas (que dizem respeito às práticas pessoais) em conjunto com funções semióticas (elementos que estão em conformidade com as configurações e são vinculadas ao objeto). As 
funções semióticas possibilitam “destacar o caráter essencialmente relacional da atividade matemática e servem para explicar algumas dificuldades e erros dos alunos” (p. 174). Com isso, os autores analisaram os principais fatores que contribuem para a resolução de problemas bayesianos e esquematizaram uma metodologia de resolução de problemas que possibilita diminuir os conflitos semióticos presentem em erros frequentes na compreensão da probabilidade condicional.

Com base nos usos e alcances das noções de práticas matemáticas e configurações de objetos e processos abordados no EOS, os autores de $\mathrm{O}_{7}$ (Pino-Fan, Godino e Font, 2015) investigaram os conhecimentos didático-matemáticos de futuros professores bacharéis em Matemática com relação ao conceito de derivada.

Fundamentados em uma abordagem qualitativa, apoiada na análise ontosemiótica que permite descrever sistematicamente a atividade matemática bem como os objetos matemáticos primários (elementos linguísticos, conceitos, proposições, procedimentos e argumentos) bem como os processos que intervêm nas práticas para a resolução da referida atividade, os autores realizaram uma caracterização dos conhecimentos dos futuros professores quanto à configuração cognitiva identificada em cada resolução.

A análise levou em consideração duas atividades - uma sobre derivada de função constante e outra sobre taxa de variação - em que se evidenciou desconexão entre os diferentes significados parciais da derivada e a necessidade de potencializar o conhecimento desse conteúdo. Para isso, os autores sugerem a necessidade de propor atividades que favoreçam o uso e identificação de objetos matemáticos, seus significados e os diferentes processos que possibilitam a solução de tarefas matemáticas.

Para avaliar o conhecimento didático-matemático de professores do Ensino Fundamental sobre o ensino de probabilidade, os autores de $\mathrm{O}_{8}$ (Vásquez e Alsina, 2015) elaboraram, construíram e validaram um questionário para avaliar aspectos relevantes do referido conhecimento. Para isso, se fundamentaram no Enfoque Ontosemiótico do Conhecimento e da Instrução Matemática e nas três categorias globais do conhecimento sobre o conteúdo matemático do professor propostas em Pino-Fan, Godino e Font (2013): conhecimento comum do conteúdo (CCC); conhecimento ampliado do conteúdo (CAC) e conhecimento especializado (CE).

Uma versão piloto do questionário foi construída, revisada e aplicada aos professores com o objetivo de coletar dados e apresentar evidências sobre aspectos das categorias de conhecimentos que os professores possuem. Com a análise das respostas, os autores concluíram que os professores apresentam nível médio em todas as categorias do conhecimento do 
conteúdo matemático, sendo que a maior dificuldade está relacionada com a compreensão da noção de sucesso seguro, cálculo e comparação de probabilidades de sucessos elementares e compreensão da independência de sucessos.

Tomando como base a noção de configuração epistêmica abordada no EOS, mais especificamente a relação objeto matemático e sistemas de prática, a pesquisa apresentada em $\mathrm{O}_{9}$ (Gordillo e Pino-Fan, 2016) trata de um estudo histórico-epistemológico da antiderivada com o objetivo de determinar a origem deste objeto matemático com relação a outros dois derivada e integral. Para isso, os autores fazem uma reconstrução do significado holístico da antiderivada a partir de significados parciais.

A noção de configuração epistêmica permitiu aos autores analisar e descrever sistematicamente os objetos matemáticos primários e seus significados que intervêm nas práticas matemáticas da antiderivada, seguindo sua evolução histórica. Com isso, os autores identificaram e caracterizaram quatro significados parciais para a antiderivada: o problema geométrico das tangentes de uma curva e a quadratura da mesma; o problema da relação fluxosfluentes; o problema sobre a relação dos diferenciais e as somatórias; o problema da identificação das funções elementares.

Utilizando o EOS centrado em ferramentas teórico-metodológicas da função semiótica no trabalho, $\mathrm{O}_{10}$ (Aznar et al., 2016) relata o estudo da construção de significados de objetos matemáticos. Para isso, os autores descrevem o uso de funções semióticas abordadas em quatro trabalhos presentes na literatura e que foram desenvolvidos por integrantes do grupo de pesquisa do qual os autores fazem parte. Os trabalhos descritos abordam as funções semióticas associadas à resolução de problemas relacionados à aprendizagem de estudantes universitários: um problema de otimização, distintas representações de números complexos, processo de significação de alguns símbolos algébricos, resolução de problemas bayesianos.

Com as descrições, os autores salientam que as funções semióticas possibilitam transparecer o nível de complexidade de uma determinada prática matemática, antecipar conflitos semióticos, avaliar detalhadamente as práticas matemáticas de estudantes, favorecer a reestruturação de sequências didáticas, contemplando as complexidades e conflitos detectados.

Para realizar uma análise do processo de instrução de uma sequência de aulas em que se explica o método de integração por partes para estudantes do segundo ano de Licenciatura em Matemática, o autor de $\mathrm{O}_{11}$ (Nieves, 2016) faz uso do modelo de análise didática proposto pelo EOS que considera cinco níveis: identificação de práticas matemáticas, elaboração de configurações didáticas, análise das trajetóridas e interações didáticas, identificação do sistema 
de normas e metanormas, avaliação da idoneidade didática do processo de instrução. $\mathrm{O}$ autor se fundamenta em uma das configurações didáticas desenvolvidas em doze seções de aulas.

Com as análises, o autor evidenciou que os estudantes apresentavam dificuldades para: determinar a ordem hierárquica para eleger qual função se denotaria por $u$ e qual denotaria por $d v$; realizar transformações de tratamentos, conversões, transferências e aplicar a regra de integração por partes; solucionar problemas pertencentes a outros contextos científicos como a Física e a Economia. A pesquisa conclui que a sequência de aulas pode ser considerada como uma degeneração mecanicista da aula formal, pois no desenvolvimento se utilizou parcialmente características próprias do paradigma formal-mecanicista. Além disso a estrutura e funcionamento não levou em consideração a complexidade ontosemiótica da integral.

\section{Discussão}

A análise dos 23 artigos cujas pesquisas se fundamentam na semiótica e a identificação dos três enfoques (semiótica peirceana, registros de representação semiótica de Duval e ontosemiótica) fornecem elementos para a constituição do retrato das abordagens semióticas nas publicações do BOLEMA.

Se, por um lado, parece haver um consenso entre educadores matemáticos de que as representações têm um papel relevante para a Matemática, seu ensino e sua aprendizagem, por outro lado a pesquisa que realizamos traz indicativos que podem, em certa medida, subsidiar este consenso.

No que se refere aos cinco artigos fundamentados na semiótica peirceana, podemos observar que os interesses dos autores contemplam, tanto aspectos filosóficos e históricos da contribuição de Peirce para a própria configuração da Matemática como ciência, quanto elementos da teoria peirceana que subsidiam as análises do desenvolvimento de atividades matemáticas por estudantes de diferentes níveis de escolaridade (ver Figura 1).

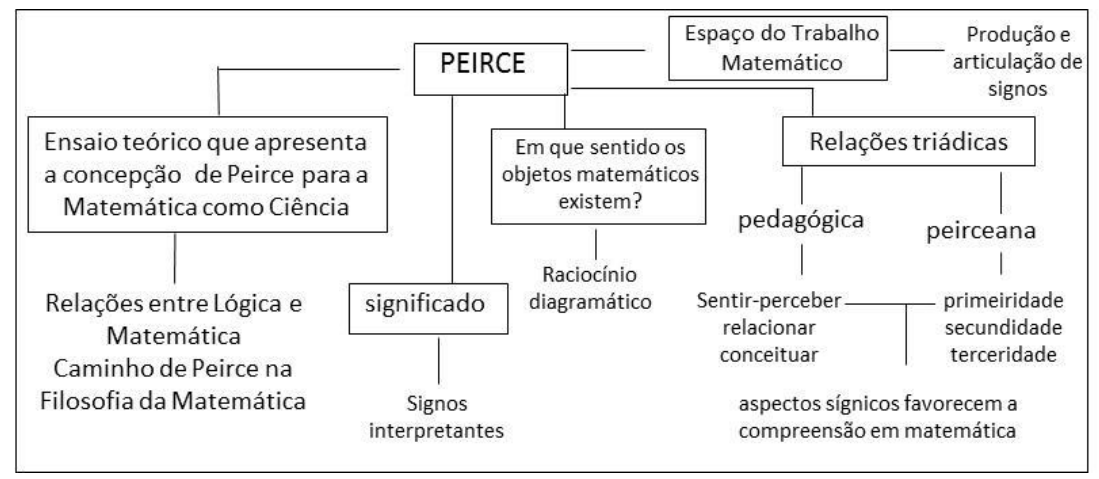

Figura 1 - Abordagens da semiótica peirceana nos artigos do BOLEMA

Fonte: Os autores (2017) 
Em termos gerais, as pesquisas baseadas em pressupostos de Peirce fornecem indicativos de que a semiótica permite conjecturar de que há uma complementaridade entre significado e referência, e, assim, a semiótica pode tornar-se um instrumento fundamental de pesquisa para entender a cognição e a epistemologia matemática.

Neste sentido respostas para a questão apontada por Otte e Barros (2015) "Em que sentido os objetos matemáticos existem?”, nos artigos analisados, vêm respaldadas na construção de Peirce, seja em termos de sua tríade que traz à tona o interpretante como um novo signo produzido pelo intérprete, seja em termos dos recursos semióticos ativados para a configuração das relações entre signos e significado na atividade matemática.

Já a relação entre a tríade peirceana e a tríade pedagógica estabelecida na análise de uma atividade matemática também evidenciada nos artigos analisados revela os alcances da teorização de Peirce com relação ao zelo pela valorização da experiência aliada às abstrações inerente aos objetos matemáticos.

Já no que se refere aos sete artigos cujo quadro teórico é constituído pela teoria da representação semiótica de Duval, nossa análise permite concluir que diferentes abordagens e aspectos da teoria foram considerados pelos autores (ver Figura 2).

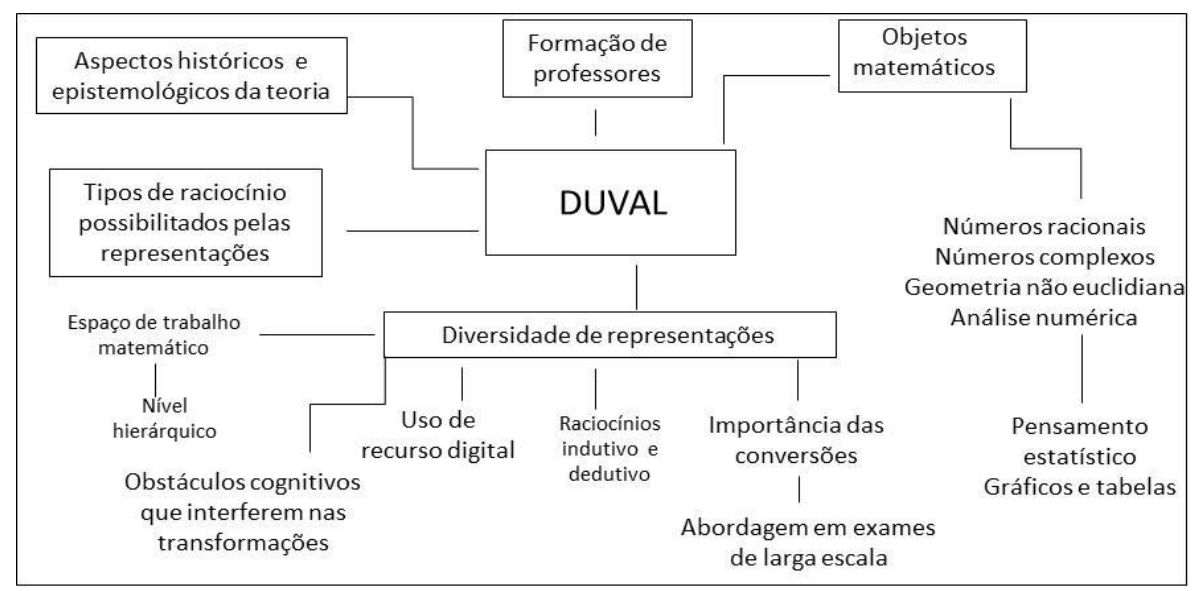

Figura 2 - Abordagens da teoria semiótica de Duval nos artigos do BOLEMA Fonte: Os autores (2017)

Se Duval (2011) coloca em discussão "Quais são os sistemas, as estruturas, as capacidades do sujeito necessárias ou mobilizadas para ter acesso aos objetos, diretamente ou por uma sequência de processos conscientes ou inconscientes?” ( p. 16), parte da resposta pode advir das pesquisas relatadas nos artigos examinados: a produção, a interpretação de representações semióticas bem como as conversões de uma representação para outra constituem a forma de acesso aos objetos matemáticos e favorecem a compreensão de seu funcionamento nas atividades matemáticas. 
Com foco em aspectos epistemológicos da teorização de Duval, nos tipos de raciocínio que o contato com diferentes representações semióticas viabiliza, na importância que a diversidade de representações tem para a compreensão dos alunos e mesmo para a reflexão dos professores sobre a organização de suas aulas, os sete artigos revelam alcances das pesquisas brasileiras neste contexto.

Na perspectiva construída por Duval, a representação semiótica não pode ter seu papel reduzido à codificação dos objetos matemáticos. Daí a indicação de Duval de proporcionar no ensino a atividade matemática de mobilizar simultaneamente ao menos dois registros de representação ou a possibilidade de trocar a todo o momento de representação. Este aspecto da teoria de Duval foi contemplado por diversos autores nas pesquisas.

Especificidades de um determinado conteúdo podem também favorecer ou oferecer obstáculos para a realização das conversões. Neste sentido as pesquisas analisadas mostram a problemática que as diferentes representações e os diferentes usos dos números racionais podem ocasionar para os estudantes.

Não obstante a realização de conversões entre registros, Duval (2003) indica que ainda mais importante do que a conversão é a coordenação entre diferentes representações e reconhecer características do mesmo objeto, que é invariante, nas diferentes representações do objeto representado. Neste contexto, caracteriza semiósis (produção de uma representação semiótica) e noésis (apreensão conceitual de um objeto matemático), esclarecendo que, não existe noésis sem semiósis, ou seja, não há compreensão de um objeto matemático sem o uso de representações semióticas desse objeto. Este uso, sobretudo, configura a noésis na medida em que coordenações progressivas entre diferentes representações são realizadas.

No que se refere a este aspecto da teoria de Duval, a análise dos artigos do BOLEMA nos leva a ponderar que, ainda que a conversão seja amplamente incentivada nas atividades, a coordenação simultânea entre mais do que duas representações não foi objeto de investigação ou de análise dos autores.

Com relação ao enfoque ontosemiótico, que foi a abordagem em onze dos vinte e três analisados, a análise semiótica a que se referem os autores e que é empreendida nos artigos, contempla um olhar sobre o que se reconhece como entidades primárias, considerando que a linguagem, as representações, os conceitos, as propriedades e os argumentos são elementos que, em atividades matemáticas, podem conferir significado aos objetos matemáticos. Além disso, os conflitos semióticos identificados por meio dessa análise revelam desajustes percebidos, tanto entre os processos de instrução regidos pelo professor e as interpretações dos alunos, quanto entre os significados pessoais e institucionais conferidos aos objetos matemáticos. 
Neste sentido, a análise semiótica serviu também para avaliar a eficácia de um processo de instrução e de uma sequência de atividades viabilizada por um objeto de aprendizagem digital para o ensino de probabilidades. A análise didática referida por alguns autores, por sua vez, mostra a relevância que a organização das atividades na sala de aula (seja com relação à estruturação das atividades, seja com relação aos padrões de interação viabilizados) para otimizar a aprendizagem matemática. Neste contexto um aspecto fundamental também é abordado nas pesquisas: o conhecimento didático-matemático dos professores.

A Figura 3 ilustra elementos do enfoque ontosemiótico e mesmo dos objetos matemáticos abordados por meio deste enfoque nos artigos analisados.

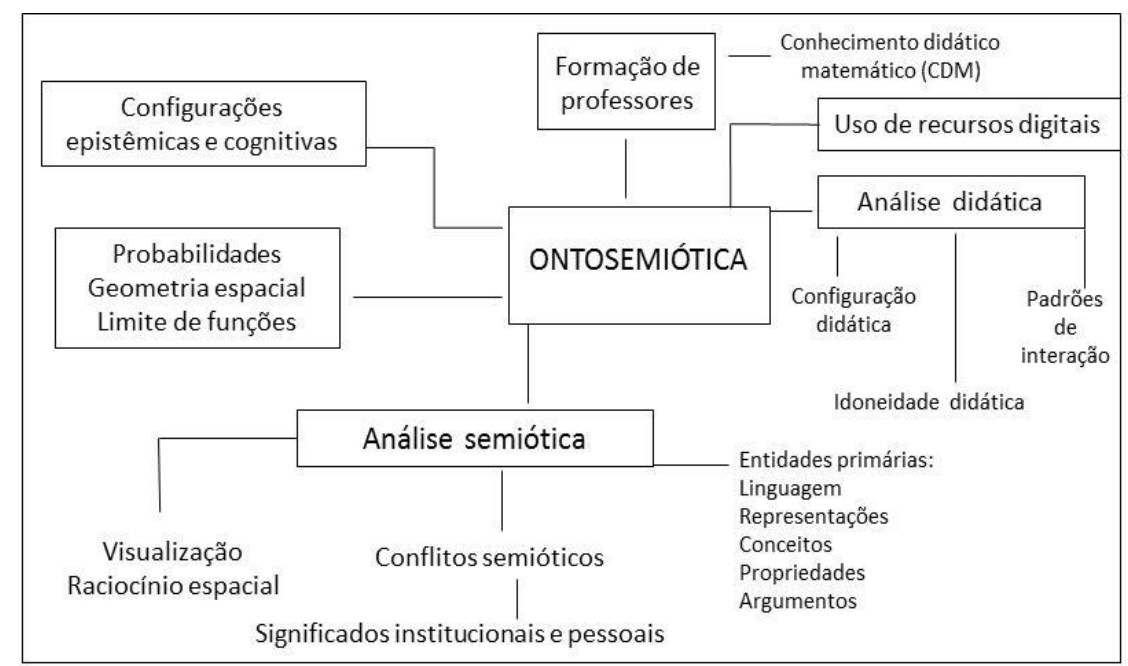

Figura 3 - Abordagens da Ontosemiótica nos artigos do BOLEMA Fonte: Os autores (2017)

Em termos gerais, a análise dos vinte e três artigos nos permite concluir que, independente do enfoque semiótico em que os autores se fundamentam, suas pesquisas se estruturam sob uma égide que estabelece que, em Matemática, o signo e o significado do objeto a ele associado são indissociáveis.

Além disso, a preocupação de que as ideias e as indicações que os enfoques semióticos oferecem para a Educação Matemática não podem ser ignoradas nos programas de formação de professores de Matemática é também uma abordagem identificada nos artigos analisados. Não está no escopo deste texto a repercussão que as abordagens semióticas estão recebendo no material didático ou nos cursos de formação para além do que os artigos analisados indicam ou, no sentido inverso, o quanto os artigos publicados no BOLEMA levam em consideração elementos da semiótica já discutidos nestes cursos e incluídos nos materiais didáticos disponíveis. Nesse sentido, a agenda de pesquisas sobre a semiótica na Educação Matemática pode contemplar essa temática. 
Em relação à quantidade de artigos que se referem a cada um dos enfoques podemos conjecturar que, possivelmente, os pressupostos de Raymund Duval e Juan Godino aparecem em maior número também pelo fato de que estes professores/educadores ainda mantêm contato com instituições brasileiras, especialmente com programas de pós-graduação. Já a teoria peirceana, ainda em menor quantidade nas publicações do BOLEMA, pode estar em processo de estruturação nas instituições brasileiras, talvez por influência de sua já consolidação em eventos internacionais. De fato, neste contexto, Presmeg et al. (2016) apresentam considerações e ponderações com relação aos usos da semiótica nas pesquisas e práticas na Educação Matemática em âmbito internacional.

\section{Referências}

ALMEIDA, L. M. W.; SILVA, K. A. P.; VERONEZ, M. R. D. Sobre a geração e a interpretação de signos em atividades de modelagem matemática. In: SEMINÁRIO INTERNACIONAL DE PESQUISA EM EDUCAÇÃO MATEMÁTICA, 6., Pirenópolis. 2015. Anais... Pirenópolis: SBEM, 2015. p. 1-13.

ASSIS, A.; FRADE, C.; GODINO, J. D. Influência dos Padrões de Interação Didática no Desenvolvimento da Aprendizagem Matemática: análise de uma atividade exploratório-investigativa sobre sequências. Bolema, Rio Claro, v. 27, n. 47, p. 733-758, dez. 2013.

CAZORLA, I. M.; GUSMÃO, T. C. Uma análise semiótica dos passeios aleatórios da Mônica: atividade para ensinar conceitos básicos de probabilidade. In: SEMINÁRIO INTERNACIONAL DE PESQUISA EM EDUCAÇÃO MATEMÁTICA, 4., Taguatinga: 2009. Anais... Taguatinga: SBEM, 2009. p. 1-3.

D’AMORE, B.; PINILLA, M. I. F.; IORI, M. Primeiros elementos de semiótica: sua presença e sua importância no processo de ensino-aprendizagem da matemática. 1. ed. São Paulo: Editora da Livraria da Física, 2015. 184p.

DUVAL, R. Registros de Representações Semióticas e Funcionamento Cognitivo da Compreensão em Matemática. In: MACHADO, S. D. A. Aprendizagem em Matemática: Registros de Representação Semiótica. Campinas: Editora Papirus, 2003. p.11-34.

DUVAL, R. Semiosis et pensée humaine: sémiotiques registres et apprentissages intellectuels. 1. ed. Bern: Peter Lang, 1995. 395 p.

DUVAL, R. Ver e ensinar a matemática de outra forma: entrar no modo matemático de pensar: os registros de representações semióticas. 1. ed. São Paulo: PROEM, 2011. 160 p.

FERREIRA, N. S. A. As pesquisas denominadas "estado da arte". Educação \& Sociedade. Campinas, ano 23, n. 79, p. 257-272, ago. 2002.

FONT, V.; PLANAS, N.; GODINO, J. Modelo para el análisis didáctico en educación matemática. Infancia y Aprendizaje. Salamanca, España, v. 33, n. 1, p. 89-105, 2010.

GARNICA, M .V. A. Peirce's Mathematical Writings: na Essay on Primary Arithmetic Books as it Relates to Mathematics Educacion. Revista Brasileira de História da Matemática. Rio Claro, v. 1, n. 2, p. 37-57, out. 2001. 
GODINO, J. D. Un enfoque ontológico y semiótico de la cognición matemática. Recherches en didactique des Mathématiques. Paris, v. 22, n. 2,3, p. 237-284, 2002.

GODINO, J. D.; BATANERO, C.; FONT, V. Un enfoque ontosemiótico del conocimiento y la instrucción matemática. 2009. Disponível em: <http://www.ugr.es/local/jgodino>. Acesso em: dezembro de 2014.

GODINO, J. D.; LLINARES, S. El interaccionismo simbólico en Educación Matemática. Revista Educación Matemática, México, D. F., v. 12, n. 1, p. 70-92, 2000.

GUSMÃO, T. R. et al. Modelo de análise do conhecimento cognitivo e metacognitivo. In: CONFERÊNCIA INTERAMENRICANA DE EDUCAÇÃO MATEMÁTICA, 13., 2011, Recife. Anais... Recife: UFPE, 2011. p. 1-10.

HALLIDAY, M. A. K. Language as social semiotic: the social interpretation of language and meaning. 1. ed. Londres: Edward Arnold, 1978. 256 p.

MENEZES, L. Desenvolvimento da comunicação matemática em professores do $1^{\circ}$ ciclo no contexto de um projecto de investigação colaborativa. In: SIMPÓSIO INTERNACIONAL DE EDUCAÇÃO MATEMÁTICA (SIEM), 16., 2005, Setúbal. Actas do XVI SIEM... Setúbal: APM, 2005. p. 349365.

OTTE, M. F.; BARROS, L. G. X. What is Mathematics, Really? Who Wants to Know? Bolema. Rio Claro, v. 29, n. 52, p. 756-772, ago. 2015.

PANERO, M.; ARZARELLO, F.; SABENA, C. The Mathematical Work with the Derivative of a Function: Teachers' Practices with the Idea of "Generic". Bolema. Rio Claro, v. 30, n. 54, p. 265-286, abr. 2016.

PINO-FAN, L.; GODINO, J.D.; FONT, V. Diseño y aplicación de un instrumento para explorar la faceta epistémica del conocimiento didáctico-matemático de futuros profesores sobre la derivada (Parte 1). REVEMAT. Florianópolis, v. 8, n. 2, p. 1-49, dez. 2013.

PEIRCE, C. S. Semiótica. 3. ed. São Paulo: Perspectiva, 2005. 340 p.

PRESMEG, $\mathrm{N}$. A semiotic view of the role of imagery and inscriptions in mathematics teaching and learning. In: CONFERENCE OF THE INTERNATIONAL GROUP FOR THE PSYCHOLOGY OF MATHEMATICS EDUCATION, 30., 2006, Prague. Proceedings .... Prague: PME, 2006. p. 19-34.

PRESMEG, N. et al. Semiotics in Mathematics Education. In: INTERNATIONAL CONGRESS ON MATHEMATICAL EDUCATION: TOPICAL SURVEYS, 13., 2016, Hamburg. Proceedings... Hamburg: Springer, 2016. p. 49.

RADFORD, L.; SCHUBRING, G.; SEEGER, F. The ubiquitousness of signs. In: RADFORD, L.; SCHUBRING, G.; SEEGER, F. (Org.). Semiotics in Mathematics Education: Epistemology, History, Classroom, and Culture. Netherlands: Sense Publishers, 2008. p. vii - X.

SÁENZ-LUDLOW, A. ; KADUNZ, G. Constructing knowledge seen as a semiotic activity. In: SáenzLudlow, A; Kadunz, G. (Org.). Semiotics as a Tool for Learning Mathematics: How to describe the construction, visualisation, and communication of mathematical concepts. Netherlands: Sense Publishers, 2016. p. 1-21.

SANTAELlA, L. A Teoria Geral dos Signos: como as linguagens significam as coisas. 2. reimpr. da 1. ed. São Paulo: Cengage Learning, 2008. 154 p. 
SANTOS, L. S.; SANTOS, M. C. Análise da conversão de registros de representação semiótica no trabalho com números racionais. In: SEMINÁRIO INTERNACIONAL DE PESQUISA EM EDUCAÇÃO MATEMÁTICA, 4., Taguatinga: 2009. Anais... Taguatinga: SBEM, 2009. p. 1-13.

VYGOTSKY, L. S. Mind in society. $1^{\text {a }}$. ed. Cambridge, MA: Harvard University Press., 1978.

\section{Artigos analisados}

ASSIS, A; FRADE, C.; GODINO, J. D. Influência dos Padrões de Interação Didática no Desenvolvimento da Aprendizagem Matemática: análise de uma atividade exploratório-investigativa sobre sequências. Bolema. Rio Claro, v. 27, n. 47, p. 733-758, dez. 2013.

AZNAR, M. A. et al. Las Funciones Semióticas como Instrumento de Diagnóstico y Abordaje de Errores. Bolema, Rio Claro, v. 30, n. 55, p. 670-690, ago. 2016.

BLANCO, T. F.; GODINO, J. D.; PEGITO, J. A. C. Razonamiento Geométrico y Visualización Espacial desde el Punto de Vista Ontosemiótico. Bolema. Rio Claro, v. 26, n. 42A, p. 39-63, abr. 2012.

CAZORLA, I. M.; GUSMÃO, T. C.; KATAOKA, V. Y. Validação de uma Sequência Didática de Probabilidade a partir da Análise da Prática de Professores, sob a Ótica do Enfoque Ontossemiótico. Bolema. Rio Claro, v. 24, n. 39, p. 537-560, ago. 2011.

COUTINHO, C. Q. S.; SILVA, M. J. F.; ALMOULOUD, S. A. Desenvolvimento do Pensamento Estatístico e sua Articulação com a Mobilização de Registros de Representação Semiótica. Bolema. Rio Claro, v. 24, n. 39, p. 495-514, ago. 2011.

FIGUEROA, S. M.; ANCHORENA, S.; DISTÉFANO, M. L. Valoración de la Idoneidad Epistémica y Cognitiva de un Proceso de Instrucción en la Resolución de Problemas Bayesianos. Bolema. Rio Claro, v. 28, n. 48, p. 169-190, abr. 2014.

FLORES, C. R. Registros de representação semiótica em matemática: história, epistemologia, aprendizagem. Bolema. Rio Claro, v. 19, n. 26, p. 77-102, 2006.

FUENTE, A. C.; ARMENTEROS, M. G.; MOLL, V. F. Análisis de un Proceso de Estudio sobre la Enseñanza del Límite de una Función. Bolema. Rio Claro, v. 26, n. 42B, p. 667-690, abr. 2012.

GAGATSIS, A. et al. Fostering Representational Flexibility in the Mathematical Working Space of Rational Numbers. Bolema. Rio Claro, v. 30, n. 54, p. 287-307, abr. 2016.

GODINO, J. D. et al. Naturaleza del Razonamiento Algebraico Elemental. Bolema. Rio Claro, v. 26, n. 42B, p. 483-511, abr. 2012

GORDILLO, W.; PINO-FAN, L. R. Una Propuesta de Reconstrucción del Significado Holístico de la Antiderivada. Bolema, Rio Claro, v. 30, n. 55, p. 535-558, ago. 2016.

HENRIQUES, A. C.; PONTE, J. P. As Representações como Suporte do Raciocínio Matemático dos Alunos quando Exploram Atividades de Investigação. Bolema. Rio Claro, v. 28, n. 48, p. 276-298, abr. 2014.

KALLEF, A. M. M. R. Registros Semióticos e Obstáculos Cognitivos na Resolução de Problemas Introdutórios às Geometrias não-Euclidianas no Âmbito da Formação de Professores de Matemática. Bolema, Rio Claro. Ano 20, n. 28, p. 69-94, 2007. 
MANECHINE, S. R. S.; CALDEIRA, A. M. A. Construção de Conceitos Matemáticos na Educação Básica numa Abordagem Peirceana. Bolema. Rio Claro, v. 23, n. 37, p. 887-904, dez. 2010.

MONZON, L. W.; GRAVINA, M. A. Uma Introdução às Funções de Variável Complexa no Ensino Médio: uma possibilidade através do uso de animações interativas. Bolema. Rio Claro, v. 27, n. 46, p. 645-661, ago. 2013

NIEVES, E.M. Análisis Didáctico a un Proceso de Instrucción del Método de Integración por Partes. Bolema. Rio Claro, v. 30, n. 55, p. 559-585, ago. 2016.

OTTE, M. F.; BARROS, L. G. X. What is Mathematics, Really? Who Wants to Know? Bolema. Rio Claro, v. 29, n. 52, p. 756-772, ago. 2015.

PANERO, M.; ARZARELLO, F.; SABENA, C. The Mathematical Work with the Derivative of a Function: Teachers' Practices with the Idea of "Generic". Bolema. Rio Claro, v. 30, n. 54, p. 265-286, abr. 2016.

PINO-FAN, L. R.; GODINO, J. D.; FONT, V. Una Propuesta para el Análisis de las Prácticas Matemáticas de Futuros Profesores sobre Derivadas. Bolema. Rio Claro, v. 29, n. 51, p. 60 - 89, abr. 2015.

SILVA, F. A. F.; SANTIAGO, M. M. L.; SANTOS, M. C. Significados e Representações dos Números Racionais Abordados no Exame Nacional do Ensino Médio - ENEM. Bolema. Rio Claro, v. 28, n. 50, p. 1485-1504, dez. 2014.

SILVA, K. A. P; ALMEIDA, L. M. W. Caminhos do Significado em Atividades de Modelagem Matemática: um olhar sobre os interpretantes. Bolema, Rio Claro, v. 29, n. 52, p. 568-592, ago. 2015.

SILVEIRA, L. F. B. Peirce e a Matemática. Bolema. Rio Claro, v. 9, n. ESPECIAL 3, p.1-12, 1994.

VÁSQUEZ, C.; ALSINA, A. Conocimiento Didáctico-Matemático del Profesorado de Educación Primaria sobre Probabilidad: diseño, construcción y validación de un instrumento de evaluación.

Bolema. Rio Claro, v. 29, n. 52, p. 681-703, ago. 2015. Aprovado em 06 de Fevereiro de 2018. 